\title{
Antigliadin Antibodies (AGA IgG) Are Related to Neurochemistry in Schizophrenia
}

\author{
Laura M. Rowland ${ }^{1 *}$, Haley K. Demyanovich ${ }^{1}$, S. Andrea Wijtenburg ${ }^{1}$, William W. Eaton ${ }^{2}$, \\ Katrina Rodriguez ${ }^{2}$, Frank Gaston ${ }^{1,}$ Daniela Cihakova ${ }^{3}$, Monica V. Talor ${ }^{3}$, Fang Liu ${ }^{\text {, }}$ \\ Robert R. McMahon ${ }^{1}$, L. Elliot Hong ${ }^{1}$ and Deanna L. Kelly ${ }^{1}$
}

\begin{abstract}
'Maryland Psychiatric Research Center, Department of Psychiatry, University of Maryland School of Medicine, Baltimore, MD, United States, ${ }^{2}$ Department of Mental Health, Johns Hopkins Bloomberg School of Public Health, Baltimore, MD, United States, ${ }^{3}$ Immunologic Disorders Laboratory, Department of Pathology, Johns Hopkins University School of Medicine, Baltimore, MD, United States
\end{abstract}

OPEN ACCESS

Edited by:

Anouk Marsman,

Copenhagen University Hospital

Hvidovre, Denmark

Reviewed by:

Jeffrey A. Stanley,

Wayne State University School of Medicine, United States

Fei Du,

Harvard Medical School,

United States

*Correspondence:

Laura M. Rowland

Irowland@mprc.umaryland.edu

Specialty section:

This article was submitted to Neuroimaging and Stimulation, a section of the journal

Frontiers in Psychiatry

Received: 31 January 2017 Accepted: 29 May 2017

Published: 19 June 2017

Citation:

Rowland LM, Demyanovich HK, Wijtenburg SA, Eaton WW Rodriguez K, Gaston F, Cihakova D, Talor MV, Liu F, McMahon RR, Hong LE and Kelly DL (2017) Antigliadin Antibodies (AGA IgG) Are Related to Neurochemistry in Schizophrenia.

Front. Psychiatry 8:104. doi: 10.3389/fpsyt.2017.00104
Inflammation may play a role in schizophrenia; however, subgroups with immune regulation dysfunction may serve as distinct illness phenotypes with potential different treatment and prevention strategies. Emerging data show that about 30\% of people with schizophrenia have elevated antigliadin antibodies of the lgG type, representing a possible subgroup of schizophrenia patients with immune involvement. Also, recent data have shown a high correlation of IgG-mediated antibodies between the periphery and cerebral spinal fluid in schizophrenia but not healthy controls, particularly AGA lgG suggesting that these antibodies may be crossing the blood-brain barrier with resulting neuroinflammation. Proton magnetic resonance spectroscopy (MRS) is a non-invasive technique that allows the quantification of certain neurochemicals in vivo that may proxy inflammation in the brain such as myoinositol and choline-containing compounds (glycerophosphorylcholine and phosphorylcholine). The objective of this exploratory study was to examine the relationship between serum AGA IgG levels and MRS neurochemical levels. We hypothesized that higher AGA IgG levels would be associated with higher levels of myoinositol and choline-containing compounds (glycerophosphorylcholine plus phosphorylcholine; GPC + PC) in the anterior cingulate cortex. Thirty-three participants with a DSM-IV diagnosis of schizophrenia or schizoaffective disorder had blood drawn and underwent neuroimaging using MRS within 9 months. We found that 10/33 (30\%) had positive AGA IgG ( $\geq 20 \mathrm{U})$ similar to previous findings. While there were no significant differences in myoinositol and GPC + PC levels between patients with and without AGA IgG positivity, there were significant relationships between both myoinositol $(r=0.475, p=0.007)$ and GPC + PC $(r=0.36, p=0.045)$ with AGA IgG levels. This study shows a possible connection of AGA IgG antibodies to putative brain inflammation as measured by MRS in schizophrenia.

Keywords: gluten, gliadin, antibody, myoinositol, GPC + PC, schizophrenia, neuroimaging, inflammation

\section{INTRODUCTION}

Several emerging lines of evidence suggest that the etiology and pathophysiology of schizophrenia may be related to inflammatory processes. Data contributing to this hypothesis include prenatal maternal infection and the subsequent pro-inflammatory response (1-3). Also, multiple studies have demonstrated increased levels of various peripheral cytokines to be elevated in people with 
first-episode or multi-episode schizophrenia (1, 2, 4-8). In addition, positron emission tomography (PET) studies have demonstrated increased binding to the $18-\mathrm{kDa}$ translocator-protein (TPSO; a marker of microglial activation) in the brains of people with schizophrenia (9-11). Finally, several genome-wide association studies have documented the presence of single-nucleotide polymorphisms in the major histocompatibility complex, genes related to immune function, that are associated with increased risk of schizophrenia (12-17).

A subset of individuals with schizophrenia may be particularly sensitive to inflammation due to immune activation to specific antigens, and this may contribute to the illness pathophysiology. This is in line with the fact that studies on inflammatory markers are not elevated in all people with schizophrenia and why inconsistent results have been shown in cross-sectional cytokine studies. The exacerbation of systemic or brain immune activation could be due to increased permeability of the mucosal epithelial tight junctions in the intestine and blood-brain barrier (18-21). Increased permeability permits entrance of pathogens, toxins, and antigens that could lead to subsequent immune response and reaction; a postulated mechanism of the brain to gut relationship mediated by inflammation. Partial support comes from a recent study indicating increased blood-cerebral spinal fluid (CSF) permeability coupled with antibody response to dietary proteins in first-episode schizophrenia (22). This study found a high correlation of IgG-mediated antibodies (e.g., antibodies to gliadin) between the periphery and CSF in schizophrenia but not healthy controls.

Positivity to immunoglobulin $\mathrm{G}$ antibodies to gliadin (AGA IgG) are observed in about $20-30 \%$ of people with schizophrenia compared to less than $10 \%$ in healthy controls (23-25). This potentially reflects gluten sensitivity (GS), which is a newly characterized syndrome defined by some intestinal but mostly extraintestinal symptoms related to the ingestion of gluten-containing food (i.e., wheat, barley, or rye) distinct from celiac disease (CD) and wheat allergy $(26,27)$. High levels of AGA IgG have also been observed in brain conditions such as ataxia (28-30). This provides further support for the gut-brain inflammation linkage. It is plausible that there is a subset of about one-quarter to one-third of the schizophrenia population that may be highly susceptible to GS-mediated peripheral and central inflammation.

Proton magnetic resonance spectroscopy (MRS) is a noninvasive technique that allows the quantification of certain neurochemicals in vivo. These neurochemicals reflect a wide variety of mechanisms that range from neuronal function to neurotransmission. MRS biochemicals such as myoinositol and glycerophosphorylcholine (GPC) plus phosphorylcholine (PC) referred to as "GPC + PC" may serve as a proxy for inflammation. Myoinositol is localized primarily in glial cells (31) and is elevated in conditions characterized by central nervous system inflammation (32) such as hepatitis $\mathrm{C}$ virus-associated encephalopathy in occipital and parietal gray and white matter (33) and multiple sclerosis in white and cortical gray matter $(34,35)$. GPC + PC levels putatively reflect cellular membrane metabolism, both synthesis and breakdown $(36,37)$, and increased levels are observed in neuroinflammatory diseases (32). Hence, spectroscopic measures of myoinositol and GPC + PC could provide insight into brain inflammation. With respect to schizophrenia, results are inconsistent regarding alterations in myoinositol and GPC + PC levels in various brain regions $(38,39)$. However, the majority of studies on schizophrenia did not examine the immune or measures related to inflammation except for one study that reported higher medial temporal lobe myoinositol in a subset of patients with elevated S100B (40).

The objective of this exploratory study was to examine the relationship between serum AGA IgG levels and MRS neurochemical measurements of the anterior cingulate cortex (ACC) in schizophrenia. Given that AGA IgG antibodies may cross the blood-brain barrier in schizophrenia (22), we hypothesized that those who tested positive for AGA IgG would have higher levels of ACC myoinositol and GPC + PC compared to those who tested negative for AGA IgG. Furthermore, we hypothesized that higher AGA IgG levels would be associated with higher levels of ACC myoinositol and GPC + PC. The ACC was the focus since it is involved in the pathophysiology of schizophrenia, as strongly supported by MRS, other neuroimaging modalities, and postmortem research $(41,42)$.

\section{MATERIALS AND METHODS}

Participants were recruited from the Maryland Psychiatric Research Center. Three hundred sixty-six patients with a DSMIV-TR diagnosis of schizophrenia or schizoaffective disorder participated in a study to measure serum AGA IgG. Of those who completed the antibody screening, 33 participants were able to also complete an MRS session; inclusion criteria for the MRS portion consisted of those between the ages of 18 and 55, and without contraindications for MR scanning (e.g., claustrophobia, metal contained in their bodies). Participants had the MRS scan and blood draw on separate occasions averaging approximately 8.8 months apart and no patient was on a gluten-free diet. All participants were evaluated for their capacity to provide informed consent before giving written consent prior to participation. The University of Maryland Baltimore Institutional Review Board approved this study.

\section{Anti-Gliadin Antibodies}

Blood was drawn and serum stored at $-80^{\circ} \mathrm{F}$ for batched analysis at the Johns Hopkins University Immune Disorders Laboratory. The sera were analyzed for AGA IgG using the INOVA kit \#708650, which is an ELISA measure for native gliadin, not a deaminated version of gliadin (linked to $C D$ ). We utilized positivity of AGA IgG according to the manufacturer cutoff of AGA IgG levels $\geq 20 \mathrm{U}$. We have also independently replicated the cutoff value in a sample of over 370 people with schizophrenia compared to 80 healthy controls with no psychiatric or medical comorbidities. Ninety percent of healthy controls fall below the cutoff and the distribution in schizophrenia is bimodal showing means in those not positive to be $<10 \mathrm{U}$ and the mean values of those who are positive to be $>40 \mathrm{U}$ (Cihakova et al., under review).

\section{MRS Acquisition and Analysis}

MR scanning was conducted on a 3-T Siemens Tim Trio equipped with a 32-channel head coil. Head position was fixed with foam 
padding to minimize movement. Anatomical T1-weighted images were acquired for spectroscopic voxel placement with a "MP-RAGE" sequence. Spectroscopic methods have been previously described (43). The spectroscopic voxel was $4.0 \mathrm{~cm} \times$ $3.0 \mathrm{~cm} \times 2.0 \mathrm{~cm}$ prescribed on the midsagittal slice and positioned parallel to the genu of the corpus callosum and scalp with the midline of the voxel corresponding to the middle of the genu of the corpus callosum. The voxel contained a mixture or rostral and dorsal ACC. Spectra were acquired with a phase rotation STEAM: TR/TM/TE $=2,000 / 10 / 6.5-\mathrm{ms}$, VOI $\sim 24 \mathrm{~cm}^{3}$, NEX $=128,2.5-\mathrm{kHz}$ spectral width, 2,048 complex points, and phases: $\varphi 1=135^{\circ}, \varphi 2=22.5^{\circ}, \varphi 13=112.5^{\circ}, \varphi \mathrm{ADC}=0^{\circ}$. The test-retest reproducibility of this sequence is excellent, as reported in both healthy volunteers (44) and participants with schizophrenia (45). A water reference $(\mathrm{NEX}=16)$ was also acquired for phase and eddy current correction as well as quantification. LCModel (6.3-0D) was used for spectral quantification (46) with a simulated basis set that contained alanine (Ala), aspartate (Asp), creatine (Cr), $\gamma$-aminobuytric acid (GABA), glucose (Glc), glutamate (Glu), glutamine (Gln), glutathione (GSH), glycine (Gly), glycerophosphocholine (GPC), lactate (Lac), myo-Inositol (mI), $\mathrm{N}$-acetylaspartate (NAA), $\mathrm{N}$-acetylaspartylglutamate (NAAG), phosphocholine (PC), phosphocreatine (PCr), phosphoroylethanolamine (PE), scyllo-Inositol (sI), and taurine (Tau). Metabolite levels are reported in institutional units, and metabolites with Cramer Rao Lower Bounds $\leq 20 \%$ were included in further analyses. The spectroscopic voxel was segmented into gray, white, and CSF tissues using SPM8 and in house MATLAB code, and the metabolite levels were corrected for the proportion of gray, white, and CSF tissue proportions (44). The following metabolites were quantified and reported: total choline (glycerophosphorylcholine + phosphorylcholine), myoinositol, glutamine, glutamine, glutamate + glutamine, glutathione, $\mathrm{N}$-acetylaspartate, and total creatine (creatine + phosphocreatine). Spectroscopic voxel location and corresponding spectrum are illustrated in Figure 1.

\section{Statistical Analyses}

Data were not normally distributed and therefore nonparametric statistical analyses were conducted. The differences in MRS measures between those patients who were "positive" (i.e., > 20 U) vs. "negative" for the AGA IgG antibodies were examined with the Kruskal-Wallis test. Spearman's correlations were performed between the MRS measures and AGA IgG levels on all participants.

\section{RESULTS}

A description of the clinical and demographic information is listed in Table 1. Briefly, the mean age of the participants was $33.8 .36 \pm 12.4(\mathrm{SD}), 52 \%$ were African-American, and $48 \%$ were Caucasian. Of these, there were 18 were males (55\%) and 15 females (45\%). Participants were of mixed illness duration with the majority $(N=28)$ having been ill for more than 2 years. Ten of the 33 participants were positive for AGA IgG GS (30\%). There were no significant differences in demographic information of those with and without positivity to IgG AGA. The overall mean IgG AGA level in the group was $17.03 \pm 24.29 \mathrm{U}$. The mean AGA IgG in the positive group was $44.61 \pm 29.09$ vs. $5.04 \pm 4.02 \mathrm{U}$ in the AGA IgG negative group $(t=20.30, \mathrm{df}=1, p<0.0001)$.

Two participants moved during MR scanning and therefore spectral quality was poor and not included in the analysis. Contrary to hypothesis, there were no significant differences in myoinositol or GPC + PC between participants who were AGA

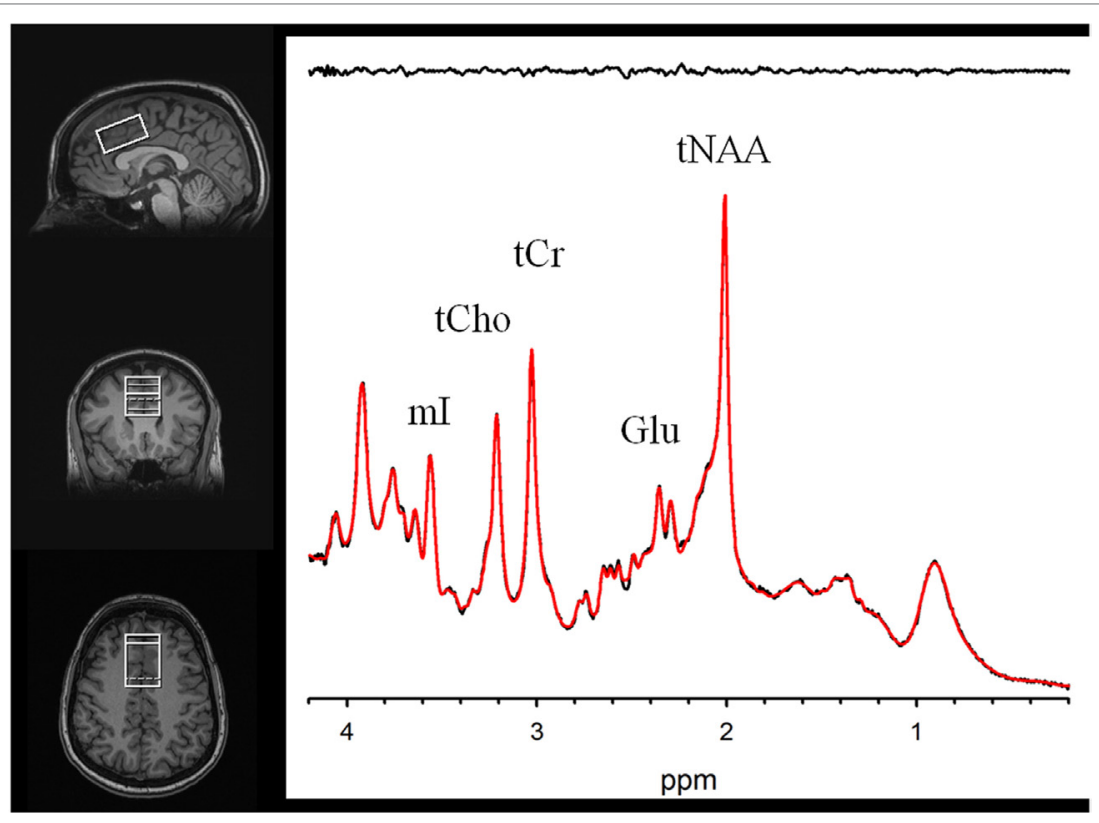

FIGURE 1 | Voxel images and a representative spectrum (black line), LCModel fit (red line), residual (black line at top). Myoinositol (ml), Phosphocreatine+Creatine (tCr), Phosphorylcholine+Glycerophosphorylcholine (tCho), Glutamate (Glu), and N-Acetylaspartate (tNAA). 
TABLE 1 | Demographic and clinical information.

\begin{tabular}{|c|c|c|c|c|}
\hline Variable & Overall group $(N=33)$ & AGA IG positive group $(N=10)$ & AGA IgG negative group $(N=23)$ & Statistic between groups \\
\hline Mean age (years) & $33.8 \pm 12.4$ & $32.0 .1 \pm 11.3$ & $34.6 \pm 13.1$ & $T=0.30, p=0.58$ \\
\hline Sex (male) & $18(55 \%)$ & $6(60 \%)$ & $12(52 \%)$ & $\chi^{2}=0.17, p=0.68$ \\
\hline \multicolumn{5}{|l|}{ Race } \\
\hline African-American & $17(52 \%)$ & $6(60 \%)$ & $11(48 \%)$ & $\chi^{2}=0.41, p=0.52$ \\
\hline Caucasian & $16(48 \%)$ & $4(40 \%)$ & 12 (52\%) & \\
\hline Schizophrenia vs. & $25(76 \%)$ & $7(70 \%)$ & $18(78 \%)$ & $\chi^{2}=0.26, p=0.61$ \\
\hline schizoaffective diagnosis & $8(24 \%)$ & $3(30 \%)$ & $5(22 \%)$ & \\
\hline Duration of illness (years) & $16.2 \pm 14.8(N=31)$ & $12.4 \pm 12.1(N=9)$ & $16.2 \pm 14.8(N=22)$ & $T=0.7, p=0.5$ \\
\hline Mean AGA IgG $(U)$ & $17.0 \pm 24.3$ & $44.6 \pm 29.1$ & $5.0 \pm 4.0$ & $T=20.3, p<0.0001$ \\
\hline
\end{tabular}

IgG positive compared to those who were IgG negative. There were no differences in the other metabolites between AGA IgGpositive and -negative groups. The correlation analyses between AGA IgG and the metabolites are reported in Table 2. Results revealed significant relationships between AGA IgG levels and both myoinositol $(r=0.475, p=0.007)$ and GPC + PC $(r=0.36, p=0.045)$ (see Figures 2 and 3). There were no significant correlations noted for glutamate, glutamine, glutathione, $N$-acetylaspartate, or creatine $(p>0.1$, Table 2$)$.

\section{DISCUSSION}

Despite the accumulating evidence of the evidence of AGA IgG antibodies in a subset of schizophrenia, little work has shown the connection of these antibodies with brain inflammation. To the best of our knowledge, this is the first study to show a relationship between peripheral AGA IgG and ACC myoinositol and GPC + PC levels. Our results also replicate the estimated prevalence of AGA IgG positivity in approximately one-third of people with schizophrenia.

Magnetic resonance spectroscopy measures of brain myoinositol and GPC + PC are thought to reflect inflammation in the brain. Myoinositol is a glial cell marker (31) and is elevated in conditions characterized by CNS inflammation such as HCVassociated encephalopathy, HIV, and multiple sclerosis (33-35, 47). Choline-containing compounds such as GPC + PC reflect cellular membrane synthesis and breakdown (37), and high levels of GPC + PC have been observed in multiple sclerosis with active lesions $(48,49)$ and HIV infection $(50)$. One study reported higher MRS myoinositol and GPC + PC levels coupled with higher microglial activation measured with PET in patients with hepatitis $C$ (51). The combination of these studies provides good support that MRS measures of myoinositol and GPC + PC proxy neuroinflammation (32). Therefore, the association between higher levels of AGA IgG and brain myoinositol and GPC + PC suggests a link between AGA IgG and CNS inflammation in schizophrenia. It is important to note that the relationships between AGA IgG and the brain metabolites were specific to myoinositol and GPC + PC only, further supporting the AGA IgG neuroinflammation link. These results are also consistent with a study showing a high-positive correlation between blood AGA IgG and CSF AGA IgG in schizophrenia patients but not healthy controls (22), suggesting greater CNS permeability and likely inflammation.
TABLE 2 | Spearman's correlations between magnetic resonance spectroscopy measures and AGA IgG in schizophrenia patients.

\begin{tabular}{lcccc}
\hline Metabolite & Mean (IU) & SD & $\boldsymbol{r}$-Value & $\boldsymbol{p}$-Value \\
\hline Glutamate $(N=31)$ & 9.12 & 0.87 & 0.104 & 0.58 \\
Glutamine $(N=30)$ & 2.18 & 0.39 & -0.1048 & 0.58 \\
Glutamate + glutamine $(N=31)$ & 10.97 & 1.21 & 0.006 & 0.97 \\
Glutathione $(N=31)$ & 2.11 & 0.35 & 0.01 & 0.96 \\
N-acetylaspartate $(N=31)$ & 9.91 & 0.90 & 0.006 & 0.97 \\
Total creatine $(N=31)$ & 8.87 & 0.92 & 0.25 & 0.18 \\
Myoinositol $(N=31)$ & 6.76 & 0.77 & 0.48 & 0.007 \\
Glycerophosphorylcholine + & 1.81 & 0.27 & 0.36 & 0.045
\end{tabular}

phosphorylcholine $(N=31)$

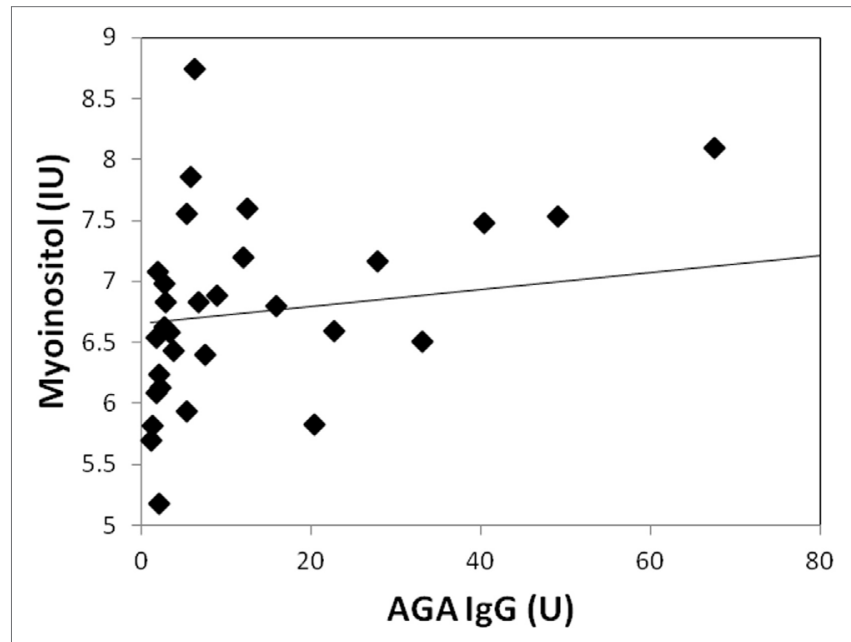

FIGURE 2 | Correlation plot showing a strong positive relationship $(r=0.48$, $p=0.007$ ) between AGA IgG and myoinositol levels. 31/33 of the participants had data available.

The ACC was the focus of this study because of its involvement in the pathophysiology of schizophrenia supported by postmortem and imaging research $(41,42)$. Volumetric MRI studies suggest that both dorsal and rostral ACC gray matter is reduced in schizophrenia (41), and proton MRS studies suggest ACC glutamatergic and GABAergic alterations in schizophrenia $(42,52,53)$. Postmortem work parallels these imaging findings as indicated by reduced ACC neuropil and altered GABAergic and glutamatergic neurons (41) in schizophrenia. If inflammation is a contributing factor to these ACC alterations is not clear, as studies focused on 


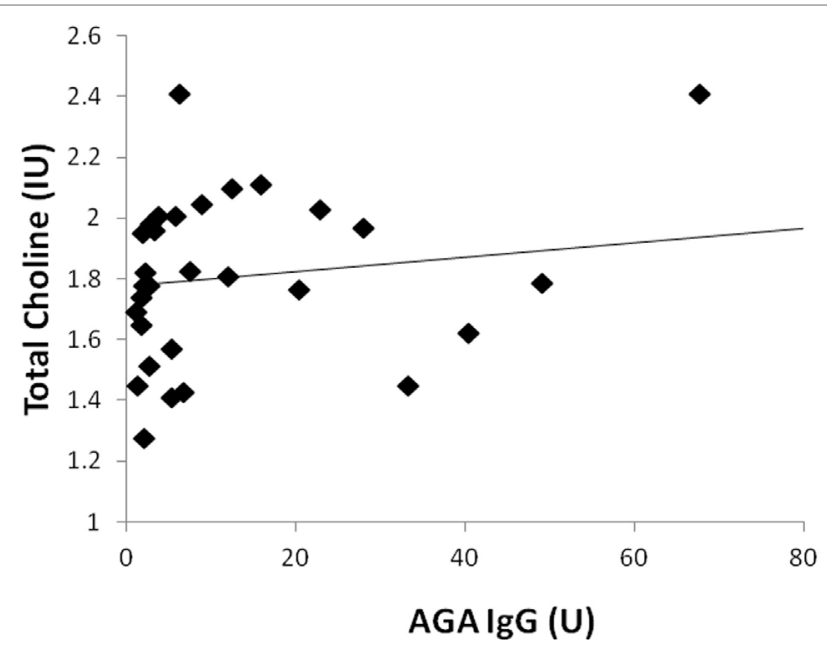

FIGURE 3 | Correlation plot showing a positive relationship $(r=0.36$, $p=0.045$ ) between AGA IgG and GPC + PC levels. 31/33 of the participants had data available.

inflammatory postmortem and PET markers in cortical regions including the ACC have been inconsistent (54). Moreover, the majority of MRS studies of the ACC in schizophrenia did not report alterations in myoinositol or GPC + PC (38); however, previous studies also did not examine specific immune parameters. It is also unclear how the current study's findings translate to other brain regions. Future studies are necessary to determine if AGA IgG is related to MRS myoinositol and GPC + PC in other brain regions.

Several study limitations are worth mentioning. First, the blood draw for AGA IgG was not on the same day as the imaging procedures; however, due to a long half-life of serum IgG antibodies ( 20 days) (55) and long-term stability of AGA IgG in patients with schizophrenia ( $<15 \%$ change in 6 months) (Kelly, unpublished data), we do not anticipate significant changes of AGA IgG levels. Second, as with the majority of studies in schizophrenia, all patients were taking antipsychotic medications, which could impact the results. We do not have the specific antipsychotic medication to include in the report. However, data support that immune involvement is independent of antipsychotic treatment (56-66). Additionally, antipsychotic medication treatment in rodents does not change GPC + PC or myoinositol levels (67). Third, we do not have clinical symptom status at the time of blood

\section{REFERENCES}

1. Meyer U, Schwarz MJ, Muller N. Inflammatory processes in schizophrenia: a promising neuroimmunological target for the treatment of negative/cognitive symptoms and beyond. Pharmacol Ther (2011) 132(1):96-110. doi:10.1016/j. pharmthera.2011.06.003

2. Fineberg AM, Ellman LM. Inflammatory cytokines and neurological and neurocognitive alterations in the course of schizophrenia. Biol Psychiatry (2013) 73(10):951-66. doi:10.1016/j.biopsych.2013.01.001

3. Moieni M, Irwin MR, Jevtic I, Breen EC, Eisenberger NI. Inflammation impairs social cognitive processing: a randomized controlled trial of endotoxin. Brain Behav Immun (2015) 48:132-8. doi:10.1016/j.bbi.2015.03.002 draw to link to symptomatology and the groups were too small to do subanalysis by gender, age, or illness duration. Only one brain region was examined, therefore brain region specificity cannot be discussed. Fourth, since causation cannot be determined from this data, it remains unknown if this sensitivity to gluten causes neuroinflammation or if antibodies are high based on neuroinflammatory process present in this group. Preclinical research is needed to determine potential causative factors related to these linked phenomena. Finally, it is not possible to ascertain if higher $\mathrm{GPC}+\mathrm{PC}$ reflects cell membrane formation or breakdown, so the results should be interpreted with caution.

In conclusion, these results suggest a possible connection of AGA IgG antibodies to putative brain inflammation as measured by MRS in schizophrenia. More research is needed to help delineate the group of people at risk for GS, which is likely a subset of schizophrenia. It is possible that interventions targeted to reduce the immune response to gluten, such as a gluten-free diet, could prove beneficial to ameliorating neuroinflammation and possibly illness symptoms.

\section{ETHICS STATEMENT}

All participants were evaluated for their capacity to provide informed consent before giving written consent prior to participation. This study was approved by the University of Maryland Baltimore Institutional Review Board.

\section{AUTHOR CONTRIBUTIONS}

LR, DK, SW, WE, KR, and DC conceptualized and designed the project. HD, SW, MT, DK, and LH acquired the data. FG, FL, SW, LR, RM, DC, KR, and DK analyzed the data. LR, HD, SW, WE, KR, FG, DC, MT, FL, RM, LH, and DK interpreted the study results, drafted the manuscript and revised it critically, and gave final approval.

\section{ACKNOWLEDGMENTS}

We thank the patient participants who kindly volunteered for this project.

\section{FUNDING}

This work is supported by National Institutes of Health (R01MH094520, R01MH085646, and R34MH100776).

4. Potvin S, Stip E, Sepehry AA, Gendron A, Bah R, Kouassi E Inflammatory cytokine alterations in schizophrenia: a systematic quantitative review. Biol Psychiatry (2008) 63(8):801-8. doi:10.1016/j.biopsych. 2007.09.024

5. Miller A, Phillips A, Gor J, Wallis R, Perkins SJ. Near-planar solution structures of mannose-binding lectin oligomers provide insight on activation of lectin pathway of complement. J Biol Chem (2012) 287(6):3930-45. doi:10.1074/jbc. M111.320341

6. Fillman SG, Cloonan N, Catts VS, Miller LC, Wong J, McCrossin T, et al. Increased inflammatory markers identified in the dorsolateral prefrontal cortex of individuals with schizophrenia. Mol Psychiatry (2013) 18(2):206-14. doi:10.1038/mp.2012.110 
7. Hope TMH, Seghier ML, Leff AP, Price CJ. Predicting outcome and recovery after stroke with lesions extracted from MRI images. Neuroimage Clin (2013) 2:424-33. doi:10.1016/j.nicl.2013.03.005

8. Hope TA, Kvitting JPE, Hope MD, Miller DC, Markl M, Herfkens RJ. Evaluation of Marfan patients status post valve-sparing aortic root replacement with 4D flow. Magn Reson Imaging (2013) 31(9):1479-84. doi:10.1016/j.mri.2013.04.003

9. van Berckel BN, Bossong MG, Boellaard R, Kloet R, Schuitemaker A, Caspers E, et al. Microglia activation in recent-onset schizophrenia: a quantitative (R)-[11C]PK11195 positron emission tomography study. Biol Psychiatry (2008) 64(9):820-2. doi:10.1016/j.biopsych.2008.04.025

10. Doorduin J, de Vries EFJ, Willemsen ATM, de Groot JC, Dierckx RA, Klein HC. Neuroinflammation in schizophrenia-related psychosis: a PET study. J Nucl Med (2009) 50(11):1801-7. doi:10.2967/jnumed.109.066647

11. Bloomfield PS, Selvaraj S, Veronese M, Rizzo G, Bertoldo A, Owen DR, et al. Microglial activity in people at ultra high risk of psychosis and in schizophrenia: an [C-11]PBR28 PET brain imaging study. Am J Psychiatry (2016) 173(1):44-52. doi:10.1176/appi.ajp.2015.14101358

12. Shi J, Levinson DF, Duan J, Sanders AR, Zheng Y, Peer I, et al. Common variants on chromosome $6 \mathrm{p} 22.1$ are associated with schizophrenia. Nature (2009) 460(7256):753-7. doi:10.1038/nature08192

13. Stefansson H, Ophoff RA, Steinberg S, Andreassen OA, Cichon S, Rujescu D, et al. Common variants conferring risk of schizophrenia. Nature (2009) 460(7256):744-7. doi:10.1038/nature08186

14. Bergen SE, O’Dushlaine CT, Ripke S, Lee PH, Ruderfer DM, Akterin S, et al. Genome-wide association study in a Swedish population yields support for greater CNV and MHC involvement in schizophrenia compared with bipolar disorder. Mol Psychiatry (2012) 17(9):880-6. doi:10.1038/mp.2012.73

15. Zhang JP, Malhotra AK. Genetics of schizophrenia: what do we know? Curr Psychiatr (2013) 12(3):24-33.

16. Schizophrenia Working Group of the Psychiatric Genomics Consortium. Biological insights from 108 schizophrenia-associated genetic loci. Nature (2014) 511(7510):421-7. doi:10.1038/nature13595

17. Sekar A, Bialas AR, de Rivera H, Davis A, Hammond TR, Kamitaki N, et al. Schizophrenia risk from complex variation of complement component 4. Nature (2016) 530(7589):177-83. doi:10.1038/nature16549

18. Axelsson R, Martensson E, Alling C. Impairment of the blood-brain barrier as an aetiological factor in paranoid psychosis. Br J Psychiatry (1982) 141:273-81. doi:10.1192/bjp.141.3.273

19. Torrey EF, Albrecht P, Behr DE. Permeability of the blood-brain barrier in psychiatric patients. Am J Psychiatry (1985) 142(5):657-8. doi:10.1176/ajp. 142.5.657

20. Bauer K, Kornhuber J. Blood-cerebrospinal fluid barrier in schizophrenic patients. Eur Arch Psychiatry Neurol Sci (1987) 236(5):257-9. doi:10.1007/ BF00380949

21. Kirch DG, Alexander RC, Suddath RL, Papadopoulos NM, Kaufmann CA, Daniel DG, et al. Blood-CSF barrier permeability and central nervous system immunoglobulin G in schizophrenia. J Neural Transm Gen Sect (1992) 89(3):219-32. doi:10.1007/BF01250674

22. Severance EG, Gressitt KL, Alaedini A, Rohleder C, Enning F, Bumb JM, et al. IgG dynamics of dietary antigens point to cerebrospinal fluid barrier or flow dysfunction in first-episode schizophrenia. Brain Behav Immun (2015) 44:148-58. doi:10.1016/j.bbi.2014.09.009

23. Dickerson F, Stallings C, Origoni A, Vaughan C, Khushalani S, Leister F, et al. Markers of gluten sensitivity and celiac disease in recent-onset psychosis and multi-episode schizophrenia. Biol Psychiatry (2010) 68(1):100-4. doi:10.1016/j.biopsych.2010.03.021

24. Sidhom O, Laadhar L, Zitouni M, Ben Alaya N, Rafrafi R, Kallel-Sellami M, et al. Spectrum of autoantibodies in Tunisian psychiatric inpatients. Immunol Invest (2012) 41(5):538-49. doi:10.3109/08820139.2012.685537

25. Okusaga O, Yolken RH, Langenberg P, Sleemi A, Kelly DL, Vaswani D, et al. Elevated gliadin antibody levels in individuals with schizophrenia. World J Biol Psychiatry (2013) 14(7):509-15. doi:10.3109/15622975.2012.747699

26. Fasano A. Surprises from celiac disease. Sci Am (2009) 301(2):54-61. doi:10.1038/scientificamerican0809-54

27. Catassi C. Gluten sensitivity. Ann Nutr Metab (2015) 67(Suppl 2):15-26. doi:10.1159/000440990

28. Hadjivassiliou V, Green MH, James RF, Swift SM, Clayton HA, Green IC. Insulin secretion, DNA damage, and apoptosis in human and rat islets of
Langerhans following exposure to nitric oxide, peroxynitrite, and cytokines. Nitric Oxide (1998) 2(6):429-41. doi:10.1006/niox.1998.0203

29. Hadjivassiliou M, Davies-Jones GA, Sanders DS, Grunewald RA. Dietary treatment of gluten ataxia. J Neurol Neurosurg Psychiatry (2003) 74(9):1221-4. doi:10.1136/jnnp.74.9.1221

30. Mittelbronn M, Krober SM, Wersebe A, Weller M, Hewer W, Meyermann R, et al. A 63-year-old man with dementia, ataxia and VI nerve palsy. Brain Pathol (2007) 17(4):466-7. doi:10.1111/j.1750-3639.2007.00091_3.x

31. Brand A, Richter-Landsberg C, Leibfritz D. Multinuclear NMR studies on the energy metabolism of glial and neuronal cells. Dev Neurosci (1993) 15(3-5):289-98. doi:10.1159/000111347

32. Chang L, Munsaka SM, Kraft-Terry S, Ernst T. Magnetic resonance spectroscopy to assess neuroinflammation and neuropathic pain. J Neuroimmune Pharmacol (2013) 8(3):576-93. doi:10.1007/s11481-013-9460-x

33. Bokemeyer M, Ding XQ, Goldbecker A, Raab P, Heeren M, Arvanitis D, et al. Evidence for neuroinflammation and neuroprotection in HCV infectionassociated encephalopathy. Gut (2011) 60(3):370-7. doi:10.1136/gut.2010. 217976

34. Bagory M, Durand-Dubief F, Ibarrola D, Comte JC, Cotton F, Confavreux C, et al. Implementation of an absolute brain 1H-MRS quantification method to assess different tissue alterations in multiple sclerosis. IEEE Trans Biomed Eng (2012) 59(10):2687-94. doi:10.1109/TBME.2011.2161609

35. Kirov II, Tal A, Babb JS, Herbert J, Gonen O. Serial proton MR spectroscopy of gray and white matter in relapsing-remitting MS. Neurology (2013) 80(1):39-46. doi:10.1212/WNL.0b013e31827bla8c

36. Maddock RJ, Buonocore MH. MR spectroscopic studies of the brain in psychiatric disorders. Curr Top Behav Neurosci (2012) 11:199-251. doi:10.1007/ 7854_2011_197

37. Harris JL, Yeh HW, Swerdlow RH, Choi IY, Lee P, Brooks WM. High-field proton magnetic resonance spectroscopy reveals metabolic effects of normal brain aging. Neurobiol Aging (2014) 35(7):1686-94. doi:10.1016/j.neurobiolaging. 2014.01.018

38. Schwerk A, Alves FD, Pouwels PJ, van Amelsvoort T. Metabolic alterations associated with schizophrenia: a critical evaluation of proton magnetic resonance spectroscopy studies. J Neurochem (2014) 128(1):1-87. doi:10.1111/ jnc. 12398

39. Plitman E, de la Fuente-Sandoval C, Reyes-Madrigal F, Chavez S, Gomez-Cruz G, Leon-Ortiz P, et al. Elevated myo-inositol, choline, and glutamate levels in the associative striatum of antipsychotic-naive patients with first-episode psychosis: a proton magnetic resonance spectroscopy study with implications for glial dysfunction. Schizophr Bull (2016) 42(2):415-24. doi:10.1093/schbul/sbv118

40. Rothermundt M, Ohrmann P, Abel S, Siegmund A, Pedersen A, Ponath G, et al. Glial cell activation in a subgroup of patients with schizophrenia indicated by increased S100B serum concentrations and elevated myo-inositol. Prog Neuropsychopharmacol Biol Psychiatry (2007) 31(2):361-4. doi:10.1016/j. pnpbp.2006.09.013

41. Fornito A, Yucel M, Dean B, Wood SJ, Pantelis C. Anatomical abnormalities of the anterior cingulate cortex in schizophrenia: bridging the gap between neuroimaging and neuropathology. Schizophr Bull (2009) 35(5):973-93. doi:10.1093/schbul/sbn025

42. Marsman A, van den Heuvel MP, Klomp DW, Kahn RS, Luijten PR, Hulshoff Pol HE. Glutamate in schizophrenia: a focused review and metaanalysis of (1)H-MRS studies. Schizophr Bull (2013) 39(1):120-9. doi:10.1093/ schbul/sbr069

43. Rowland LM, Summerfelt A, Wijtenburg SA, Du X, Chiappelli JJ, Krishna N, et al. Frontal glutamate and gamma-aminobutyric acid levels and their associations with mismatch negativity and digit sequencing task performance in schizophrenia. JAMA Psychiatry (2016) 73(2):166-74. doi:10.1001/ jamapsychiatry.2015.2680

44. Wijtenburg SA, Gaston FE, Spieker EA, Korenic SA, Kochunov P, Hong LE, et al. Reproducibility of phase rotation STEAM at 3T: focus on glutathione. Magn Reson Med (2014) 72(3):603-9. doi:10.1002/mrm.24959

45. Bustillo JR, Rediske N, Jones T, Rowland LM, Abbott C, Wijtenburg SA. Reproducibility of phase rotation stimulated echo acquisition mode at 3T in schizophrenia: emphasis on glutamine. Magn Reson Med (2016) 75(2): 498-502. doi: $10.1002 / \mathrm{mrm} .25638$

46. Provencher SW. Estimation of metabolite concentrations from localized in vivo proton NMR spectra. Magn Reson Med (1993) 30(6):672-9. doi:10.1002/ mrm.1910300604 
47. Harezlak J, Buchthal S, Taylor M, Schifitto G, Zhong J, Daar E, et al. Persistence of HIV-associated cognitive impairment, inflammation, and neuronal injury in era of highly active antiretroviral treatment. AIDS (2011) 25(5):625-33. doi:10.1097/QAD.0b013e3283427da7

48. Arnold DL, Matthews PM, Francis GS, O’Connor J, Antel JP. Proton magnetic resonance spectroscopic imaging for metabolic characterization of demyelinating plaques. Ann Neurol (1992) 31(3):235-41. doi:10.1002/ana. 410310302

49. Bitsch A, Kuhlmann T, Stadelmann C, Lassmann H, Lucchinetti C, Bruck W. A longitudinal MRI study of histopathologically defined hypointense multiple sclerosis lesions. Ann Neurol (2001) 49(6):793-6. doi:10.1002/ana.1053

50. Young AC, Yiannoutsos CT, Hegde M, Lee E, Peterson J, Walter R, et al. Cerebral metabolite changes prior to and after antiretroviral therapy in primary HIV infection. Neurology (2014) 83(18):1592-600. doi:10.1212/ wnl.0000000000000932

51. Grover VP, Pavese N, Koh SB, Wylezinska M, Saxby BK, Gerhard A, et al. Cerebral microglial activation in patients with hepatitis $\mathrm{C}$ : in vivo evidence of neuroinflammation. J Viral Hepat (2012) 19(2):e89-96. doi:10.1111/ j.1365-2893.2011.01510.x

52. Rowland LM, Krause BW, Wijtenburg SA, McMahon RP, Chiappelli J, Nugent KL, et al. Medial frontal GABA is lower in older schizophrenia: a MEGA-PRESS with macromolecule suppression study. Mol Psychiatry (2016) 21(2):198-204. doi:10.1038/mp.2015.34

53. Wijtenburg SA, Wright SN, Korenic SA, Gaston FE, Ndubuizu N, Chiappelli J, et al. Altered glutamate and regional cerebral blood flow levels in schizophrenia: a 1H-MRS and pCASL study. Neuropsychopharmacology (2017) 42(2): 562-71. doi:10.1038/npp.2016.172

54. Trepanier MO, Hopperton KE, Mizrahi R, Mechawar N, Bazinet RP. Postmortem evidence of cerebral inflammation in schizophrenia: a systematic review. Mol Psychiatry (2016) 21(8):1009-26. doi:10.1038/mp.2016.90

55. Brekke OH, Sandlie I. Therapeutic antibodies for human diseases at the dawn of the twenty-first century. Nat Rev Drug Discov (2003) 2(1):52-62. doi:10.1038/ nrd984

56. Beumer W, Drexhage RC, De Wit H, Versnel MA, Drexhage HA, Cohen D. Increased level of serum cytokines, chemokines and adipokines in patients with schizophrenia is associated with disease and metabolic syndrome. Psychoneuroendocrinology (2012) 37(12):1901-11. doi:10.1016/j.psyneuen. 2012.04.001

57. Guo J, Clausen DM, Beumer JH, Parise RA, Egorin MJ, Bravo-Altamirano K, et al. In vitro cytotoxicity, pharmacokinetics, tissue distribution, and metabolism of small-molecule protein kinase D inhibitors, kb-NB142-70 and kbNB165-09, in mice bearing human cancer xenografts. Cancer Chemother Pharmacol (2013) 71(2):331-44. doi:10.1007/s00280-012-2010-z

58. Drexhage RC, Knijff EM, Padmos RC, Heul-Nieuwenhuijzen LVD, Beumer W, Versnel MA, et al. The mononuclear phagocyte system and its cytokine inflammatory networks in schizophrenia and bipolar disorder. Expert Rev Neurother (2010) 10(1):59-76. doi:10.1586/ern.09.144

59. Drexhage RC, Hoogenboezem TA, Cohen D, Versnel MA, Nolen WA, van Beveren NJ, et al. An activated set point of T-cell and monocyte inflammatory networks in recent-onset schizophrenia patients involves both pro-and anti-inflammatory forces. Int J Neuropsychopharmacol (2011) 14(6):746-55. doi:10.1017/S1461145710001653

60. Leonard BE, Schwarz M, Myint AM. The metabolic syndrome in schizophrenia: is inflammation a contributing cause? J Psychopharmacol (2012) 26 (5 Suppl):33-41. doi:10.1177/0269881111431622

61. Miller BH, Zeier Z, Xi L, Lanz TA, Deng S, Strathmann J, et al. microRNA-132 dysregulation in schizophrenia has implications for both neurodevelopment and adult brain function. Proc Natl Acad Sci U S A (2012) 109(8):3125-30. doi:10.1073/pnas.1113793109

62. Mondelli V, Howes O. Inflammation: its role in schizophrenia and the potential anti-inflammatory effects of antipsychotics. Psychopharmacology (Berl) (2014) 231(2):317. doi:10.1007/s00213-013-3383-3

63. Severance EG, Alaedini A, Yang S, Halling M, Gressitt KL, Stallings CR, et al. Gastrointestinal inflammation and associated immune activation in schizophrenia. Schizophr Res (2012) 138(1):48-53. doi:10.1016/j.schres.2012. 02.025

64. Severance EG, Gressitt KL, Stallings CR, Origoni AE, Khushalani S, Leweke FM, et al. Discordant patterns of bacterial translocation markers and implications for innate immune imbalances in schizophrenia. Schizophr Res (2013) 148(1):130-7. doi:10.1016/j.schres.2013.05.018

65. Steiner J, Bogerts B, Sarnyai Z, Walter M, Gos T, Bernstein H-G, et al. Bridging the gap between the immune and glutamate hypotheses of schizophrenia and major depression: potential role of glial NMDA receptor modulators and impaired blood-brain barrier integrity. World J Biol Psychiatry (2012) 13(7):482-92. doi:10.3109/15622975.2011.583941

66. Stojanovic A, Martorell L, Montalvo I, Ortega L, Monseny R, Vilella E, et al. Increased serum interleukin-6 levels in early stages of psychosis: associations with at-risk mental states and the severity of psychotic symptoms. Psychoneuroendocrinology (2014) 41:23-32. doi:10.1016/j.psyneuen. 2013.12.005

67. Bustillo J, Barrow R, Paz R, Tang J, Seraji-Bozorgzad N, Moore GJ, et al. Longterm treatment of rats with haloperidol: lack of an effect on brain $\mathrm{N}$-acetyl aspartate levels. Neuropsychopharmacology (2006) 31(4):751-6. doi:10.1038/ sj.npp. 1300874

Conflict of Interest Statement: The authors declare that the research was conducted in the absence of any commercial or financial relationships that could be construed as a potential conflict of interest.

Copyright (c) 2017 Rowland, Demyanovich, Wijtenburg, Eaton, Rodriguez, Gaston, Cihakova, Talor, Liu, McMahon, Hong and Kelly. This is an open-access article distributed under the terms of the Creative Commons Attribution License (CC BY). The use, distribution or reproduction in other forums is permitted, provided the original author(s) or licensor are credited and that the original publication in this journal is cited, in accordance with accepted academic practice. No use, distribution or reproduction is permitted which does not comply with these terms. 